\title{
Represión y "aniquilamiento de la subversión" durante los gobiernos peronistas de la década del setenta
}

\author{
Repression and "annihilation of subversion" during the peronist governments in \\ the seventies
}

\author{
Esteban Damián Pontoriero \\ estebanpontoriero@hotmail.com \\ Escuela Interdisciplinaria de Altos Estudios/ \\ Universidad Nacional de San Matrtín-CONICET, \\ Argentina
}

Recepción: 02 Febrero 2021

Aprobación: 03 Mayo 2021

Publicación: 01 Marzo 2022

Cita sugerida: Pontoriero, E. D. (2022). Represión y “aniquilamiento de la subversión” durante los gobiernos peronistas de la década del setenta. Sociohistórica, 49, e159. https://doi.org/10.24215/18521606e159

\begin{abstract}
Resumen: El artículo estudia la represión política como una acción de "guerra interna" explorando el abordaje antisubversivo en la política de defensa de los gobiernos peronistas de 1973-1976. Usando la legislación, las órdenes y las directivas de las autoridades políticas y los debates parlamentarios, primero analizo cómo el Ejército se hizo cargo de la represión. Luego, doy cuenta de la política de defensa de María Estela Martínez de Perón (julio de 1974-marzo de 1976). Finalmente, estudio las normativas gubernamentales que desde 1975 habilitaron el uso de fuerzas militares en el orden interno. Se reconstruye el vínculo entre excepcionalidad jurídica y contrainsurgencia.
\end{abstract}

Palabras clave: Argentina, Represión, Contrainsurgencia, Defensa, Ejército.

Abstract: The article studies political repression as an "internal war" action exploring the countersubversive approach in the defense policy of the Peronist governments of 1973-1976. Using legislation, orders and directives from political authorities and parliamentary debates, I first analyze how the Army took over the repression. Then, I give an account of the defense policy of María Estela Martínez de Perón (July 1974-March 1976). Finally, I study the government regulations that since 1975 have enabled the use of military forces in the internal order. The link between legal exceptionality and counterinsurgency is rebuilt.

Keywords: Argentina, Repression, Counterinsurgency, Defense, Army.

\section{INTRODUCCIÓN}

Durante un debate por una nueva ley de defensa en 1975, la mímesis de algunos dirigentes políticos con las fuerzas militares se expresaba de manera clara y contundente, expresando un verdadero signo de la época. El representante tucumano por el Partido Vanguardia Federal, Juan Carlos Cárdenas, daba su opinión de las tropas que actuaban en un operativo represivo en Tucumán, y decía:

el uniforme verde que hubieron de ponerse [los diputados] para entrar en la zona de operaciones es como un símbolo del que debemos ponernos todos, en una lucha que nos afecta a todos, una lucha en la que no puede haber cómodos ni indiferentes (Ministerio de Defensa, 2010, p. 230). 
Se trataba de una muestra del grado de acuerdo al que habían llegado civiles y militares respecto de la llamada "lucha antisubversiva".

Desde la última década, los estudios sobre la represión política se ocupan de diversos temas, entre ellos la historia del estado de excepción en los gobiernos constitucionales y dictatoriales en el período 1955-1976. La investigación de los gobiernos peronistas de los años setenta incluye el conjunto de discursos, normativas legales y prácticas represivas, algunas asociadas con acciones criminales. Se analiza la continuidad con los años de Arturo Frondizi (1958-1962) y la "Revolución Argentina" (1966-1973), así como la articulación con la "depuración interna" del movimiento peronista contra los sectores de izquierda vinculados a Montoneros durante 1973-1976. Para estos autores, el estado de excepción permitió que el Ejército desarrollara medidas de represión y exterminio. Además, presentan una cronología enfocada en la continuidad entre gobiernos constitucionales y dictatoriales, actores político-civiles y militares, y legalidad e ilegalidad (Pittaluga, 2006; Pittaluga, 2010; Ranalletti, 2009; Eidelman, 2010; Servetto, 2010; Franco, 2012; Águila, 2013; Servetto y Paiaro, 2013).

El concepto de estado de excepción define la situación en que el soberano decide la suspensión del orden jurídico para ejecutar las medidas de seguridad y represión que considera necesarias para asegurar el orden frente a una amenaza interna o externa. Carl Schmitt y Giorgio Agamben señalan que su puesta en vigor se conecta con la defensa del estado de derecho en casos que lo ponen en riesgo. Como afirman estos autores, el estado de excepción representa una paradoja debido a que suspende el marco legal que viene a resguardar (Schmitt, 1985; Schmitt, 2005; Schmitt, 2006; Agamben, 2007; Agamben, 2010).

Mi hipótesis en este trabajo es que en los gobiernos peronistas de los años 1973-1976 se produjo una la asimilación de la represión política con una operación de guerra interna, lo que da cuenta del enfoque antisubversivo en la política de defensa a través de la legislación, las órdenes y las directivas emanadas del poder ejecutivo y en los debates parlamentarios. Esta línea de indagación se enlaza con los trabajos citados más arriba, por lo que busca ser una contribución a los estudios sobre represión tal como los he caracterizado. Al hablar de "enfoque antisubversivo" o "enfoque contrainsurgente", que son sinónimos, me refiero a un abordaje de la defensa que incorpora la seguridad interna a sus preocupaciones, en el marco de la Guerra Fría y la "amenaza comunista". Sin embargo, en este artículo me centro en el aspecto militar de la contrainsurgencia: el uso de las Fuerzas Armadas (FF. AA.) para la represión y el exterminio. Ello no debería hacer perder de vista que existen otros aspectos asociados a esta tarea, que conciernen a las acciones del gobierno en el campo de la salud, la educación y la asistencia social (Brocades Zaalberg, 2012). Por lo tanto, espero haber delimitado claramente mi objeto de estudio.

En la primera parte se estudia el contexto de violencia política y represión legal e ilegal en que, a través de diferentes medidas de emergencia, las FF. AA., con el Ejército a la cabeza, retomaron el control del accionar represivo. En la segunda parte se analiza la política de defensa de María Estela Martínez de Perón (julio de 1974-marzo de 1976) a partir del proyecto de ley de defensa de 1975 y el debate parlamentario que se dio en torno a ella. Por último, en la tercera parte se estudia la legislación y las normativas gubernamentales que organizaron la acción represiva de las FF. AA. a partir de febrero de 1975.

\section{Del ABORDAJE POLICIAL A UN ENFOQUe MILITAR DE LA REPRESIóN}

La asunción presidencial de Héctor Cámpora el 25 de mayo de 1973 y su breve gobierno representaron un momento de triunfo para los sectores juveniles, sindicales combativos e intelectuales, luego de una prolongada dictadura militar entre 1966 y 1973. Las diferentes agrupaciones juveniles -con la coordinación de la organización político-militar Montoneros- integraban un frente de masas denominado la Tendencia Revolucionaria. Lo integraban la Juventud Peronista, el Movimiento de Villeros Peronistas, la Unión de Estudiantes Secundarios, la Juventud Universitaria Peronista, la Agrupación Evita de la Rama Femenina y 
el Movimiento de Inquilinos Peronistas, para nombrar solo a los grupos más destacados (Svampa, 2003; De Riz, 2007; Franco, 2012; Larraquy, 2017; Merele, 2017).

Cámpora planteó un cambio de orientación profundo en materia represiva, en contraste con los gobiernos dictatoriales de la "Revolución Argentina". A fines de mayo el Congreso otorgó una amnistía a alrededor de quinientos presos políticos encarcelados en los años anteriores, luego de una masiva movilización popular en diferentes penales de todo el país. El epicentro geográfico se localizó en la cárcel de Villa Devoto, Capital Federal, donde se encontraba la mayor parte de los detenidos. El presidente indultó a los presos en la noche de su asunción, medida apoyada por la mayoría de los legisladores dos días después.

Se anularon las llamadas "leyes represivas": el cuerpo de normativas que otorgaban amplias facultades a las FF. AA. en el orden interno y que promovían la persecución ideológica sobre militantes comunistas y otras expresiones de la izquierda. Si bien los diputados y senadores no derogaron la Ley de defensa nacional 16.970, sancionada por el dictador Juan Carlos Onganía en 1966, la posibilidad de usar fuerzas militares quedó extremadamente limitada, no solo por razones legales sino sobre todo por su debilitamiento político.

La corta duración de la presidencia de Cámpora representó, en muchos sentidos, una excepción antes que una tendencia a largo plazo en lo concerniente con el abordaje represivo. Las tensiones al interior del movimiento peronista estallaron, en lo que se conoció como la "Masacre de Ezeiza", el 20 de junio con motivo del retorno de Perón al país. Las conducciones de las organizaciones juveniles peronistas y Montoneros planearon una gran demostración de poder, esperando que Perón comprendiera que eran el sector mayoritario dentro del movimiento. Los grupos ortodoxos - a cargo de la organización y la custodia del palco desde el que hablaría Perón- abrieron fuego contra las columnas integradas por sus adversarios intrapartidarios. Mientras tanto, el avión que transportaba al "viejo líder" se desvió de su destino original, y aterrizó en el aeródromo de Morón. Al otro día, Perón se expresó públicamente y conminó a todos sus seguidores a subordinarse al orden constitucional. No hizo menciones directas sobre lo ocurrido, pero ya comenzaba a mostrar su alineamiento con los sectores tradicionales del sindicalismo y el partido. El 4 de julio Cámpora presentó la renuncia a su jefe político; debilitado ya en extremo, el presidente nunca había gozado del respaldo necesario para fortalecer su autoridad.

Desde la asunción de Raúl Lastiri (julio de 1973-octubre de 1973) hubo un paulatino avance de un enfoque que desde 1975 colocaría a las FF. AA. al mando de un vasto operativo represivo. En estos años, las tensiones intrapartidarias del peronismo se cruzaron con un diagnóstico sobre una situación de "guerra interna" proveniente del ámbito militar y extendido entre diversos actores de la sociedad civil.

En octubre de 1973, en el comienzo de la presidencia de Perón, la respuesta del gobierno y la dirigencia partidaria basó una parte de su accionar en un conjunto de medidas clandestinas, fundamentalmente mediante los ataques realizados por los grupos paraestatales. El movimiento peronista contaba con antecedentes de agrupaciones como el Comando de Organización o la Concentración Nacional Universitaria, que desde los meses anteriores a los hechos de Ezeiza se encontraban operando contra los militantes vinculados a los sectores juveniles y contestatarios.

Las organizaciones armadas de orientación marxista produjeron desde comienzos de 1974 una serie de ataques a cuarteles, guarniciones militares y secuestros, entre los que se destaca el ataque del Ejército Revolucionario del Pueblo (ERP) en enero contra el Regimiento de Caballería Blindada $\mathrm{N}^{\circ}$ 10, Húsares de Pueyrredón, en la localidad bonaerense de Azul. Si bien el operativo fracasó, el jefe del regimiento, coronel Camilo Gay, su esposa Hilda Casaux y el soldado conscripto Daniel González resultaron muertos. Otra consecuencia del hecho fue que en su fuga los atacantes se llevaron como rehén al teniente coronel Jorge Ibarzábal, luego de la intervención de fuerzas de la Marina y la Fuerza Aérea movilizadas desde bases cercanas. El grupo de militantes del ERP, por su parte, contó dos muertos.

Luego de los hechos de Azul, la dirigencia política oficialista y opositora comenzó a discutir en el Congreso el endurecimiento de las penas de los delitos vinculados con el accionar de las organizaciones armadas. Los diputados aprobaron una serie de modificaciones al Código Penal a fines de enero, en medio de un gran 
desacuerdo expresado por varios representantes de la oposición y el oficialismo. Para el legislador del Partido Liberal de Corrientes Ricardo Balestra, el proyecto podía dividirse en dos partes:

una de ellas, meramente numérica, de escala penal: el agravamiento de las penas. Y otra creativa o recreativa de algunas figuras (...) que pretende de ese modo colocar dentro de la sanción de la ley algunos de los crímenes que se suponen cometidos por elementos terroristas (Congreso de la Nación, 1974, p. 5537). ${ }^{1}$

Los delitos incluían el secuestro, las amenazas, la portación de armas de guerra sin autorización, el sabotaje en ámbitos de trabajo, la incitación a la violencia colectiva y el uso de documentación falsa o adulterada, entre varios otros (Congreso de la Nación, 1974). La gran mayoría de estas acciones ya se encontraban asociadas con la "subversión" en la doctrina contrainsurgente del arma terrestre, lo cual verifica una sintonía con lo incorporado a la normativa (Pontoriero, 2016).

La extensión de los sujetos y actividades a perseguir habilitaba una acción represiva en gran escala. Según el representante del Partido Revolucionario Cristiano Horacio Sueldo -integrado al oficialismo-, la reforma del Código Penal

pretende, pues, aplicar el tratamiento de la asociación ilícita y de la incitación a la violencia a ciertas actividades que no se delimitan claramente en el proyecto, permitiendo así con esa generalidad que se descargue la sanción sobre actitudes, discursos o declaraciones de tipo político o gremial, cuya importancia, cuya justificación misma se podrá discutir, pero que de ninguna manera deberían ser asimiladas al delito (Congreso de la Nación, 1974, p. 5541).

Desde este punto de vista, la ambigüedad de la normativa habilitaba al gobierno a reprimir un variado conjunto de expresiones de la protesta social y el activismo político.

El uso de las fuerzas policiales o de las FF. AA. fue otro de los ejes de la discusión. En concordancia con la opinión mayoritaria, algunos diputados manifestaban que la "subversión" debía reprimirse por medio de las fuerzas de seguridad. El representante del Partido Demócrata de Mendoza Francisco Moyano señalaba:

no creo que el Estado argentino esté actualmente desarmado frente a la guerrilla y a los agentes del caos. (...) Es indispensable la dotación suficiente del personal policial que necesita el país, tanto en la policía federal como en las policías provinciales (Congreso de la Nación, 1974, p. 5550).

En contraste con esta opinión, otros diputados empezaban a plantear el recurso a las FF. AA., sosteniendo que la legislación represiva de la "Revolución Argentina”, que seguía vigente, podía resultar de utilidad. El legislador del Partido Liberal de Corrientes Tomás Arbo afirmaba:

El gobierno tiene medios suficientes para combatir y reprimir la subversión guerrillera y la delincuencia organizada. Hay todo un aparato legal y organizativo con los medios y competencias adecuados. Cabe citar, por ejemplo, la ley 16.970 sobre planeamiento y acción para la seguridad de la Nación; la ley 19.081 que incluye normas complementarias de la anterior (...). A través de todo ello, el Poder Ejecutivo puede utilizar todos los medios del Estado, incluidas las fuerzas armadas, hasta aplicar, si conviene, las leyes que regulan el estado de sitio y el de guerra interno (Congreso de la Nación, 1974, p. 5550).

El gobierno también se encaminó hacia un enfoque contrainsurgente, tal como puede verse en el decreto secreto 1.302, sancionado por Perón en abril de 1974 (PEN, 2017). Esta normativa señalaba que el presidente aprobaba el inicio de las operaciones "Topo" y "Yacaré" para casos de "conflictos graves". De acuerdo con el anexo $\mathrm{N}^{\circ} 1$ del decreto: "el Estado Argentino enfrenta la subversión armada de grupos radicalizados que buscan la toma del poder para modificar el sistema de vida democrático pluripartidista”. Para ocuparse de esta amenaza, se disponía "eliminar las acciones subversivas violentas y no violentas, las causas que las provocan y consolidar espiritual y materialmente el régimen democrático comoámbito de realización integral del hombre". Se ordenaba avanzar en la "elaboración de planes sectoriales para superar el conflicto en los campos: Interior-Económico-Social y Militar". Esto expresaba una concepción de la "guerra antisubversiva" que excedía el ámbito exclusivamente militar, lo que evidencia una afinidad con la llamada doctrina "de la seguridad nacional” (DSN) estadounidense, que contemplaba la dimensión política. Para ejecutar esta acción 
estaba prevista la creación de un organismo coordinado por el ministro del Interior en el que estuvieran representadas todas las carteras del ejecutivo y el Estado Mayor Conjunto (PEN, 2017).

La incorporación de las FF. AA. a la seguridad interna encuentra así un antecedente destacado, algo que hasta el momento se había relativizado porque Perón sostenía públicamente lo contrario. Es mucho más conocida su predilección por un abordaje policial de la lucha contra las organizaciones armadas. Sin embargo, el rol crucial de Perón se puede ver en el decreto. Con respecto a su aplicación, el anexo indicaba que: "a. El Plan Nacional para superar el conflicto será elevado al Poder Ejecutivo antes del 15 de agosto de 1974 para su aprobación y aplicación inmediata en la forma en que éste determine. b. El Plan Militar sólo será puesto en ejecución por orden expresa del Poder Ejecutivo". (PEN, 2017, p. 2). Más allá de que seguramente este conjunto de medidas quedó desactivado por el fallecimiento de Perón, ocurrido el $1^{\circ}$ de julio de ese año, el decreto constituye un antecedente importante del sistema represivo que comenzaría a desplegarse durante el mandato de su esposa. ${ }^{2}$

A fines de septiembre de 1974, el Congreso reforzó los medios represivos del Estado mediante la Ley 20.840, también llamada "Ley de seguridad nacional". Esta normativa habilitaba la detención de las personas por motivos ideológicos cuando se intentara alterar el "orden constitucional y la paz social", criminalizaba los conflictos sindicales cuando las huelgas fueran declaradas ilegales, y creaba penas para periodistas o responsables de medios de comunicación que publicitaran acciones o imágenes vinculadas con la “subversión”. Además, se permitía expulsar del país a los extranjeros que incurrieran en alguno de los delitos mencionados y determinaba la pérdida de la ciudadanía para los argentinos naturalizados (Congreso de la Nación Argentina, 1974).

Durante el mandato de Perón, la policía se encargó del grueso de la "lucha antisubversiva" y las FF. AA. solamente intervinieron en casos puntuales, sin estar sujetas a un plan orgánico (Franco, 2012). A diferencia de lo ocurrido en la etapa de la "Revolución Argentina", esta vez sería un gobierno constitucional y peronista, el de Martínez de Perón, el que recorrería el camino de la reintroducción de los militares para la represión (Franco, 2012). Desde comienzos del año siguiente el Ejército tomó parte activa en las acciones de seguridad interna gracias a una serie de leyes y decretos, junto con la creación de un estado de amplia excepcionalidad jurídica por parte de los poderes ejecutivo y legislativo, con el corolario de la declaración del estado de sitio en noviembre de 1974 (Novaro y Palermo, 2006; De Riz, 2007; Franco, 2012; Merele, 2017). ${ }^{3}$

\section{UNA POLÍTICA DE DEFENSA PARA LA GUERRA INTERNA}

En febrero de 1975, el poder ejecutivo convocó al Ejército para destruir el "foco guerrillero" instalado por el ERP en la provincia de Tucumán. La estrategia combinó la eliminación de los apoyos en la ciudad y las operaciones en el monte. La represión legal e ilegal y la acumulación de fuerzas militares y de seguridad produjeron los resultados esperados: en el último trimestre de 1975 quedaban solo tres pelotones aislados, al tiempo que los guerrilleros perdían combatientes en los descensos a la ciudad y las emboscadas en el monte. Esto se profundizaría luego del golpe de marzo de 1976 hasta el aniquilamiento de la compañía al año siguiente (Novaro y Palermo, 2006; De Riz, 2007; Franco, 2012; Merele, 2017). El accionar represivo del Ejército adquirió un carácter nacional mediante el decreto 2.772 de Ítalo Luder después del ataque de Montoneros a una unidad militar en Formosa, mientras la presidenta estaba de licencia en octubre de 1975 (Fraga, 1988; Franco, 2012).

En los años de Martínez de Perón se buscó crear una estructura legal para la defensa y la represión mediante una nueva ley: el 19 de noviembre de 1975 se envió a la Cámara de Diputados un proyecto para reemplazar la Ley 16.970 sancionada por Onganía. ${ }^{4}$ Ambas normativas compartían varias similitudes: una misma concepción de la defensa asociada a los conceptos de seguridad y desarrollo, una caracterización de la 
amenaza enfocada en el "enemigo interno" y la disposición de un conjunto de medidas de intervención de las FF. AA. en tareas de represión (Ministerio de Defensa, 2010).

Algunos diputados identificaban claramente las continuidades con la "Revolución Argentina". En el debate parlamentario, el legislador de la UCR Eduardo Massolo expresó: "este proyecto de ley que ha tomado estado parlamentario no es nada más ni nada menos que la repetición de la ley Onganía [la Ley de defensa 16.970], más la incorporación de los tres decretos dictados durante el interinato Luder" (Ministerio de Defensa, 2010, p. 191) $)^{5}$ El propio poder ejecutivo reconocía en un mensaje enviado al Congreso que su objetivo era unificar en una nueva normativa los cambios introducidos por los decretos de octubre de 1975 (Ministerio de Defensa, 2010). Por lo tanto, el proyecto se inscribía en un enfoque de la defensa que abordaba la seguridad interna en clave antisubversiva, un asunto que hundía sus raíces en la década anterior, y que llegaba hasta la ley de defensa sancionada por la dictadura de Onganía (Pontoriero, 2018).

La coyuntura de 1975 mostraba un importante grado de acuerdo entre el gobierno y la oposición en materia de "lucha contra la subversión". La mayoría de los legisladores estaba convencida de un supuesto estado de guerra interna, un diagnóstico compartido por el Ejército (Pontoriero, 2016). Se afirmaba que los representantes políticos deberían realizar su aporte dotando al gobierno de una ley que facilitara el uso de las FF. AA. contra la "subversión". El diputado oficialista Campos señalaba: "es evidente que estamos frente a una verdadera guerra en lo interno, frente a una guerra artera que escapa a toda norma tradicional y debe ser asumida con toda decisión” (Ministerio de Defensa, 2010, p. 234). Desde la oposición, el demócrata progresista Evaristo Monsalve tuvo expresiones similares: "el factor que debemos tener principalmente en cuenta es que el país está en guerra. Conscientemente todos debemos reconocer que el país está en guerra, contra enemigos visibles y contra enemigos invisibles" (Ministerio de Defensa, 2010, p. 276).

En el proyecto de ley de defensa se optó por evitar una definición clara de la amenaza interna. Como lo explicaba el legislador oficialista José Lazzarini, "la falta de definición puede facilitar la aplicación de la ley porque da la elasticidad necesaria" (Ministerio de Defensa, 2010, p. 194). Puede suponerse que el partido gobernante y sus apoyos en la oposición promovían una normativa que pudiera incluir un campo amplio de actores individuales y colectivos para reprimir. Al mismo tiempo, se hacía eje en las acciones contrarias a la ley antes que en una ideología específica, por lo que se creaba una definición extensa del enemigo. El diputado de la Confederación Popular Federalista-Unión Conservadora Carlos Acevedo expresó que la "subversión" remitía a:

hechos que tienden a destruir el orden público, aspecto este último, al cual ya me he referido muy específicamente. Y anoto, en tren de caracterización, que la subversión persigue una finalidad política; diría, en tal sentido, que es una especie de los delitos políticos. Pero en lo que concierne a la ley debo anotar lo siguiente: se trata de la acción violenta, es decir, la acción caracterizada por el empleo de la fuerza que se ejerce sobre las cosas o que constriñe a las personas a infringir los deberes preceptuados por la ley (Ministerio de Defensa, 2010, pp. 320-321).

La práctica de la violencia, entendida en un sentido amplio, estaba en el centro de la definición. Junto a las organizaciones político-militares surgió un elemento novedoso: la inclusión de las organizaciones paraestatales vinculadas con el peronismo ortodoxo. Diversos legisladores oficialistas y opositores concordaban en que el gobierno debía erradicar la "violencia de izquierda" y la "de derecha". El diputado radical Massolo manifestaba que el problema era tanto "la acción subversiva de la ultraizquierda como la acción fascista de la derecha, particularmente las tres A" (Ministerio de Defensa, 2010, p. 194) ${ }^{6}$. Con una opinión similar se expresaba desde otra parte del espectro político el diputado del Partido Comunista Jesús Mira, quien señalaba:

la intensificación del terrorismo aún no perseguido de la Triple A y de la ultraderecha fascista sirve, en nuestra opinión, a siniestros planes. Pero también sirven a esos fines los terroristas de ultraizquierda, que consideran que las revoluciones no obedecen a leyes determinadas que rigen el desarrollo de la sociedad sino a la voluntad todopoderosa de individuos aislados (Ministerio de Defensa, 2010, p. 237). 
Como ha demostrado Marina Franco, la caracterización binaria de la violencia política de los primeros años setenta se constituyó en la matriz de interpretación predominante; a ella adscribieron dirigentes políticos, empresariales, religiosos, sindicales, y la prensa (Franco, 2012). El marco interpretativo basado en la guerra de aparatos militares de "izquierda" y de "derecha" fue previo a la construcción de la llamada "teoría de los dos demonios". Esta fue una interpretación del pasado de violencia política revolucionaria y de represión clandestina ejecutada por las FF. AA. y por las fuerzas de seguridad que vivió la Argentina en los años setenta. Se elaboró durante la década del ochenta por parte de diversos actores políticos e intelectuales vinculados con el gobierno de Raúl Alfonsín (1983-1989). Según esta "teoría”, la violencia política "de extrema izquierda", representada por las organizaciones político-militares, y de "extrema derecha", corporizada por las FF. AA., se abatió sobre una sociedad "inocente" y "víctima”, lo que creó un cuadro de situación que metafóricamente fue descripto como el de un "infierno" construido por los "dos demonios" enfrentados (Franco, 2015).

En relación con las causas que generaron la aparición de la "subversión", la dirigencia política mostraba la incorporación del diagnóstico castrense influido por la DSN. En efecto, la interpretación de algunos diputados se caracterizaba por contemplar las variables económicas, sanitarias y educativas. En su crítica al proyecto de ley, el representante de la UCR Massolo señalaba que en la normativa

no están comprendidos los aspectos más importantes de la vida de una nación, que son los que pueden ayudar a las Fuerzas Armadas a luchar con éxito y eficacia contra la subversión, es decir, los problemas económico-sociales, de la salud, culturales, políticos, etcétera (Ministerio de Defensa, 2010, p. 193).?

En apoyo de esta postura, su compañero de bancada Horacio Hueyo afirmaba que

la falta de desarrollo encierra igualmente el germen de la lucha. En el submundo de la necesidad se generan sentimientos que suelen utilizar la violencia como válvula de escape, creando caminos por donde avanzan ideologías que justamente se apoyan en la frustración imperante (Ministerio de Defensa, 2010, p. 273).

Opiniones cercanas o similares también fueron expresadas por los representantes de los demás partidos políticos, lo que marca la gran extensión de este diagnóstico. ${ }^{8}$

Los legisladores que estaban en contra del avance represivo hicieron saber su parecer. El diputado de la Unión del Pueblo Argentino Héctor Sandler manifestó que "no hay ningún paralelismo entre la seguridad interna y la seguridad externa; si bien una y otra se condicionan, lo cierto es que se consiguen por vías absolutamente diferentes" (Ministerio de Defensa, 2010, p. 246). De igual manera, el diputado Luis Lucena del Partido Revolucionario Cristiano expresaba que "esta ley no es una ley de Defensa Nacional, sino que simplemente atiende a una parcialidad: 'la seguridad nacional'” (Ministerio de Defensa, 2010, p. 318). Por su parte, Héctor Portero, del Partido Intransigente, se oponía a caracterizar la situación interna como la de un escenario bélico; expresaba que "el concepto de guerra interna no es apropiado. (...) Más bien habría que hablar de traición a la Patria” (Ministerio de Defensa, 2010, p. 303). A pesar de destacarse por su originalidad, este punto de vista era minoritario: el proyecto de ley contó con un gran apoyo y se aprobó.

El análisis del debate parlamentario muestra que la opinión favorable a la orientación contrainsurgente del poder ejecutivo se basó en dos aspectos: la defensa del Estado y la asunción de la existencia de una situación de emergencia. Estado de excepción y guerra interna son dos conceptos claves, entonces, para comprender la lógica que está operando entre la mayor parte de la dirigencia política. Según lo expresó el diputado oficialista Lazzarini, "tenemos que partir de la base de que el Estado tiene derecho, dadas las causas graves a que se refiere la ley, a su autodefensa" (Ministerio de Defensa, 2010, p. 179). Esta postura encontraba voces aliadas en la oposición: el diputado demócrata progresista Monsalve expresó:

En algunos casos llega a desconocer prácticamente derechos que están consagrados en la Constitución Nacional, lo cual sólo puede admitirse con el argumento que hizo uno de los oradores que me precedieron, cuando habló, precisamente, del estado de necesidad. Ese estado de necesidad es lo que nos permite soslayar escrúpulos principistas relativos a las instituciones, porque por encima de ellos está la vida misma de la Nación y de las instituciones que pretendemos preservar (Ministerio de Defensa, 2010, p. 274). 
De acuerdo con el razonamiento de Raphaëlle Branche, puede afirmarse que la incorporación de la seguridad interna a la esfera de la defensa hizo que la legislación se adaptara a las necesidades de la "guerra contra la subversión". ${ }^{9}$ El papel que cumplió la dirigencia política no puede dejarse de lado. Corresponde, entonces, mostrar cuáles fueron las características de esa política de defensa.

\section{EL GOBIERNO ORDENA LA “GUERRA CONTRA LA SUBVERSIÓN"}

En septiembre de 1975 tuvo lugar una reunión en la que participaron las autoridades máximas de las tres armas junto al presidente interino Luder (Novaro y Palermo, 2006; Acuña y Smulovitz, 2007). De acuerdo con diversas fuentes, en el encuentro se decidió una estrategia represiva basada en acciones clandestinas y el exterminio de los opositores. ${ }^{10}$ En una entrevista con el periodista Ceferino Reato, el exgeneral y expresidente de facto Videla, quien en 1975 era el comandante general del Ejército, explicó que la reunión fue convocada por Luder para conocer la opinión de las FF. AA. sobre cómo debería ejecutarse la acción contra las organizaciones armadas.

En ese marco, se presentaron cuatro cursos de acción posibles. El $\mathrm{N}^{\circ} 1$ implicaba un alto grado de centralización en la conducción político-militar y la ejecución sobre el terreno. Este método permitiría reducir la cantidad de "errores" o "excesos" cometidos por la tropa, aunque seguramente se necesitaría de mucho tiempo para alcanzar la victoria. Los cursos de acción $\mathrm{N}^{\circ} 2$ y $\mathrm{N}^{\circ} 3$, según Videla, planteaban una mayor libertad de los mandos inferiores. $\mathrm{El} \mathrm{N}^{\circ} 4$ se basaba en el despliegue por todo el territorio nacional de las FF. AA. y las fuerzas de seguridad, bajo el mando de las primeras, con el objetivo de encontrar y "aniquilar" al enemigo. Con un grado elevado de libertad de acción, propio de la ejecución descentralizada, los "errores" y "excesos" podían multiplicarse, aunque se prometía eliminar el "terrorismo" en un año y medio. En su relato, Videla señala que Luder optó por este último curso de acción (Reato, 2012). No obstante, esta afirmación debe tomarse con cuidado, debido a las posibles intenciones exculpatorias de quien las formuló, y debe quedar expuesta a futuras confirmaciones.

La puesta en práctica del operativo represivo a escala nacional se basó en la centralización de los mandos político-militares. El decreto 2.770 de octubre creó el Consejo de Seguridad Interna, dirigido por el presidente e integrado por sus ministros y los comandantes en jefe de las tres armas. Mediante esa normativa se estableció el Consejo de Defensa, a cargo del ministro de esa área e integrado por los comandantes generales de las FF. AA. y el Estado Mayor Conjunto. Mientras que el primero se encargaba de la "guerra antisubversiva" a través de una estrategia general, el segundo asesoraba la planificación, coordinación y conducción de la estrategia militar propiamente dicha. De igual forma, el proyecto de ley de defensa discutido y aprobado por los diputados a fines de 1975 incluía la formación de dos consejos con funciones similares, con la única diferencia de que el Consejo de Seguridad Interna pasaría a llamarse "de Seguridad Nacional" (Ministerio de Defensa, 2010).

El eje de la acción estuvo marcado por la orden del gobierno de "aniquilar a la subversión". El decreto 261 -mediante el que se dio inicio al "Operativo Independencia” en febrero de 1975- establecía que "el comando general del Ejército procederá a ejecutar las operaciones militares que sean necesarias a efectos de neutralizar y/o aniquilar el accionar de los elementos subversivos que actúan en la provincia de TUCUMAN" (Ministerio de Defensa, 2010, p. 123) ${ }^{11}$. Esta orden fue extendida a todo el territorio nacional a partir de octubre a través del decreto 2.772 , que afirmaba:

las Fuerzas Armadas bajo el Comando Superior del presidente de la Nación que será ejercido a través del Consejo de Defensa procederán a ejecutar las operaciones militares y de seguridad que sean necesarias a efectos de aniquilar el accionar de los elementos subversivos en todo el territorio del país (Ministerio de Defensa, 2010, p. 129).

Ese mes el Consejo de Defensa emitió la "Directiva del Consejo de Defensa nro 1/75 (Lucha contra la subversión)", que ordenaba a las fuerzas militares y de seguridad "aniquilar los elementos constitutivos de 
las organizaciones subversivas a través de una presión constante sobre ellas" (Consejo de Defensa, 1975a, p. 3). Estas normativas incorporaban el concepto de "aniquilamiento", proveniente del vocabulario militar y referente al exterminio físico del enemigo (Pontoriero, 2016).

La organización de la "guerra antisubversiva" se estructuró a partir de la subordinación de las fuerzas de seguridad a las FF. AA. Junto con la creación de los consejos de Seguridad Interna y de Defensa, el decreto 2.770 expresaba como una de sus atribuciones la de "planear y conducir el empleo de las Fuerzas Armadas, fuerzas de seguridad y fuerzas policiales para la lucha contra la subversión” (Ministerio de Defensa, 2010, p. 125). Además, la Policía Federal y el Servicio Penitenciario Nacional pasarían a depender del Consejo de Defensa. Estos aspectos también se habían incorporado en el proyecto de ley de defensa de 1975 (Ministerio de Defensa, 2010).

De acuerdo con la evaluación de las autoridades políticas y militares, la tarea represiva debía concentrarse en las principales ciudades del país. Según la directiva emitida por el Consejo de Defensa, "dado que la subversión ha desarrollado su mayor potencial en los grandes centros urbanos y en algunas áreas colindantes, el esfuerzo principal de la ofensiva será llevado sobre el eje TUCUMÁN, CÓRDOBA, SANTA FE, ROSARIO, CAPITAL FEDERAL, LA PLATA" (Consejo de Defensa, 1975a, p.3) ${ }^{12}$. Para las FF. AA, las prioridades -en orden descendente según su nivel de peligrosidad- serían: Tucumán, la Capital Federal y la ciudad de La Plata, Córdoba, y luego Rosario y Santa Fe (Consejo de Defensa, 1975a).

El gobierno se dispuso a apoyar las operaciones mediante la "acción psicológica", buscando combinar el aspecto militar con su costado político. Se consideraba que las prácticas represivas debían realizarse junto a otras medidas - fundamentalmente de propaganda- dirigidas a separar a quienes habían definido como "enemigos internos" del resto de la población. Según el agregado a la directiva "nro 1/75 (Lucha contra la subversión)", llamado "Régimen Funcional de Acción Psicológica", el Consejo de Defensa afirmaba que la "subversión" dedicaba grandes esfuerzos a la "guerra psicológica”, motivo por el que era necesario ocuparse de ese campo (Consejo de Defensa, 1975b, p. 2). Se prescribía que las FF. AA. se encargaran de "orientar la opinión pública nacional e internacional a fin de que tome conciencia que la subversión es un 'enemigo indigno de esta patria"' (Consejo de Defensa, 1975a, p. 3).

Esta opinión también fue expresada por algunos diputados durante el debate parlamentario. Desde la oposición, el radical López afirmaba que "no se puede combatir a la guerrilla ni con las Fuerzas Armadas ni con todos los organismos de seguridad, ni con una ley de defensa si no se cuenta con el apoyo y la comprensión de todo el pueblo argentino" (Ministerio de Defensa, 2010, p. 293) ${ }^{13}$. En línea con este planteo, la "Directiva...” indicaba que así se lograría "aislar a la subversión de todo apoyo tanto de tipo interno como externo" (Consejo de Defensa, 1975a, p. 3). Una vez que eso se consumara, según el llamado "Régimen Funcional de Acción Psicológica”, se podrían "crear las condiciones sicosociales que contribuyan al aniquilamiento de la subversión en todas sus formas y a consolidar el estilo de vida nacional" (Consejo de Defensa, 1975b, p. 5). Las tareas de acción política para sostener la operación represiva se hallaban estrechamente vinculadas con las operaciones militares más duras.

En un contexto de grave crisis económica, conflictividad política, actuación de las organizaciones armadas, represión y violencia política paraestatal, se produjo el derrocamiento de Martínez de Perón (Svampa, 2003; De Riz, 2007). De forma acertada, diferentes autores resaltaron el peso que las FF. AA. tuvieron en ese desenlace (García, 1995; Rouquié, 1998). El pretorianismo militar -es decir, la intervención sistemática del actor castrense en la política- explica una parte de la historia. Sin embargo, en una obra ya clásica aunque reciente, Marina Franco advirtió sobre la necesidad de incorporar al actor político-civil a esta explicación (Franco, 2012). La crisis final del orden democrático a mediados de los setenta fue también el corolario de un proceso de destrucción del estado de derecho promovido a través de medidas de excepción por un gobierno constitucional (Franco, 2012). 


\section{CONSIDERACIONES FINALES}

Hacia fines de 1975, el gobierno constitucional de Martínez de Perón había dado forma a un entramado de leyes y normativas de defensa que les devolvían a las FF. AA., en particular al Ejército, el control de la seguridad interna desde una perspectiva contrainsurgente. No obstante, el abandono del abordaje policial de la "guerra contra la subversión" poseía un antecedente destacado: alrededor de un año antes, Perón había sancionado un decreto secreto que, aunque no llegó a implementarse, en muchos aspectos ya señalaba el camino de la incorporación del actor militar a la esfera del orden interno. Esta normativa mantenía una estrecha relación con las otras leyes aprobadas en 1974, antes y después de la muerte del líder del peronismo. Por consiguiente, la operación represiva iniciada en 1975 por orden del gobierno de Martínez de Perón se inscribía en una línea que tenía sus puntos de contacto con la gestión de su predecesor.

Otro aspecto para remarcar es el alto grado de acuerdo entre el gobierno, sus representantes en el Congreso y una gran parte de los referentes de otros partidos políticos respecto de la necesidad de emprender la lucha contra las organizaciones armadas, desde una perspectiva bélica y a partir del establecimiento de un estado de excepción. No es casual que las normativas de 1974 y el proyecto de ley de defensa de 1975 se hayan aprobado por amplias mayorías. Los legisladores que apoyaron esta normativa -al igual que el gobierno- expresaron un discurso atravesado por el abordaje contrainsurgente, lo que muestra la pervivencia de elementos más cercanos al pensamiento francés (un enfoque más militar de la represión), y otros, tributarios de la DSN (una preocupación por las causas culturales, sociales y económicas del surgimiento de la "subversión").

Por medio de un conjunto de leyes y decretos, entre febrero y octubre de 1975 el gobierno nacional reconstruyó un marco jurídico para abordar la seguridad interna en clave antisubversiva, derivado del creciente avance de la violencia armada de las organizaciones político-militares. De esa manera, se habilitó al Ejército y a las demás FF. AA. a intervenir nuevamente en las tareas represivas entendidas como parte de la "lucha contra la subversión".

De acuerdo con los actores civiles y militares encargados de combatirla, la amenaza incluía una cantidad variada de participantes, más allá de los militantes armados encuadrados en las organizaciones políticomilitares, tanto marxistas como peronistas. La contribución de los gobiernos peronistas de la década del setenta al proceso de incorporación de las FF. AA. a las tareas de represión interna no puede ser soslayada: la legitimidad discursiva y legal que les otorgaron a las FF. AA. fue central para la reinstalación del actor militar como garante de la seguridad interior y referente de la defensa del Estado ante la llamada "amenaza subversiva" (Franco, 2012).

Los referentes políticos y los líderes militares fueron protagonistas centrales de la creciente imposición de medidas de excepción durante los últimos años democráticos de la década del setenta, antes del inicio de la última dictadura militar. El abordaje contrainsurgente de la seguridad interna y la excepcionalidad jurídica delineados por la dirigencia política fortalecieron el rol de las FF. AA. y contribuyeron a habilitar la represión en una escala exponencialmente brutal.

\section{ReFERENCiAS}

Acuña, C., y Smulovitz, C. (2007). "Militares en la transición argentina: del gobierno a la subordinación constitucional", en Anne Pérotin-Dumon (editora), Historizar el pasado vivo en América Latina. Santiago de Chile: Universidad Alberto Hurtado. Recuperado de http://www.historizarelpasadovivo.cl/downloads/ acunasmulovitz.pdf

Agamben, G. (2007) Estado de excepción. Buenos Aires: Adriana Hidalgo editora.

Agamben, G. (2010) Homo Sacer. El poder soberano y la nuda vida. Valencia: Editorial Pre-Textos. 
Águila, G. (2013) "La represión en la historia reciente argentina: fases, dispositivos y dinámicas regionales”, en Gabriela Águila y Luciano Alonso (editores), Procesos represivos y actitudes sociales: entre la España franquista y las dictaduras del Cono Sur (pp. 97-122). Buenos Aires: Prometeo Libros.

Brocades Zaalberg, T. (2012) “Counterinsurgency and peace operations", en Paul Rich e Isabelle Duyvesteyn (editores), The Routledge handboook of insurgency and counterinsurgency(pp. 80-97). Nueva York: Routledge.

Congreso de la Nación Argentina (1974) Diario de sesiones de la Cámara de Diputados, Vol. VIII.Buenos Aires: Imprenta del Congreso.

Congreso de la Nación Argentina (1974) Anales de Legislación Nacional, t. XXXIV-D. Buenos Aires: Imprenta del Congreso.

Consejo de Defensa (1975a) "Directiva del Consejo de Defensa n 1/75 (Lucha contra la subversión)”. Recuperado de http://www.desaparecidos.org/nuncamas/web/document/militar/175.htm

Consejo de Defensa (1975b) "Régimen Funcional de Acción Psicológica".

De Riz, L. (2007) Historia argentina 8: la politica en suspenso: 1966-1976. Buenos Aires: Paidós.

Eidelman, A. (2010) "El desarrollo de los aparatos represivos del Estado argentino durante la "Revolución Argentina", 1966-1973", Tesis de Doctorado inédita, Universidad de Buenos Aires.

Fraga, R. (1988) Ejército: del escarnio al poder (1973-1976). Buenos Aires: Planeta.

Franco, M. (2012). Un enemigo para la nación. Orden interno, violencia y "subversión". Buenos Aires: Fondo de Cultura Económica.

Franco, M. (2015) “La 'teoría de los dos demonios' en la primera etapa de la posdictadura”. En Claudia Feld y Marina Franco (editoras), Democracia, hora cero: actores, politicas y debates en los inicios de la posdictadura (pp. 23-80). Buenos Aires: Fondo de Cultura Económica.

García, P. (1995) El drama de la autonomía militar. Argentina bajo las Juntas Militares. Madrid: Alianza Editorial.

Larraquy, M. (2017) Argentina. Un siglo de violencia politica. Buenos Aires: Sudamericana.

Merele, H. (2017) La "depuración" ideológica del peronismo en General Sarmiento 1973-1974: una aproximación al proceso represivo durante los años setenta constitucionales a partir del caso de Antonio "Tito" Deleroni. La Plata: Universidad Nacional de La Plata. Facultad de Humanidades y Ciencias de la Educación; Los Polvorines: Universidad Nacional de General Sarmiento; Misiones: Universidad Nacional de Misiones). Recuperado de http://www.memoria.fahce.unlp.edu.ar/libros/pm.524/pm.524.pdf.

Ministerio de Defensa (2010) Antecedentes legales y parlamentarios, 1944-1986.

Colección de debates parlamentarios de la defensa nacional. Buenos Aires:

Ministerio de Defensa. Recuperado de https://www.academia.edu/1869920/ Debates_Parlamentarios_de_la_Defensa_Nacional._Ley_de_Defensa_Nacional_23.554_1988_._Antecedentes_pa rlamentarios_

Novaro, M. y Palermo, V. (2006) La dictadura militar 1976-1983: del golpe de Estado a la restauración democrática. Buenos Aires: Paidós.

Pittaluga, R. (2006) "La memoria según Trelew". En Sociohistórica. Cuadernos del CISH, n 19-20 (pp. 81-111). Recuperado de http://www.memoria.fahce.unlp.edu.ar/art_revistas/pr.3610/pr.3610.pdf

Pittaluga, R. (2010) “El pasado reciente argentino: interrogaciones en torno a dos problemáticas”, en Bohoslavsky, E., et. al., (editores), Problemas de historia reciente del Cono Sur (pp. 23-35). Buenos Aires: Prometeo Libros.

Poder Ejecutivo Nacional (2017) Boletín Oficial de la República Argentina.

Pontoriero, E. (2016) “'Preparativos de guerra': Ejército, doctrina antisubversiva y planes represivos en los orígenes del terror de Estado, 1973-1976". Revista Universitaria de Historia Militar, 2016, vol. 5 (319-339). Recuperado de http://ruhm.es/index.php/RUHM/article/view/226

Pontoriero, E. (2018) “La seguridad interna como campo de batalla de la 'guerra revolucionaria': contrainsurgencia y defensa nacional en los ámbitos político y militar en Argentina (1963-1970)”. Boletín del Instituto de Historia Argentina y Americana "Dr. Emilio Ravignani", 48 (pp. 84-120). Recuperado de http://ppct.caicyt.gov.ar/ index.php/ravignani/article/view/12073/pdf_1 
Ranalletti, M. (2009) “Contrainsurgencia, catolicismo intransigente y extremismo de derecha en la formación militar argentina. Influencias francesas en los orígenes del terrorismo de Estado (1955-1976)”, en Daniel Feierstein (editor), Terrorismo de estado y genocidio en América Latina (pp. 249-281). Buenos Aires: Prometeo Libros.

Reato, C. (2012) Disposición Final. La dictadura por dentro y la confesión de Videla sobre los desaparecidos. Buenos Aires: Sudamericana.

Rouquié, A. (1998) Poder militar y sociedad política en la Argentina II, 1943-1973. Buenos Aires: Emecé.

Servetto, A. (2010) 73/76. El gobierno peronista contra las provincias "montoneras". Buenos Aires: Siglo XXI.

Servetto, A. y Paiaro, M. (2013) “Violencia y represión. Los discursos de María Estela Martínez de Perón (1974-1976)”. Anos 90, Revista do Programa de Pós-Graduação em História da Universidade Federal do Rio Grande do Sul, vol. 20 (pp. 353-383). Recuperado de https://seer.ufrgs.br/anos90/article/view/29246.

Schmitt, C. (1985) La dictadura. Desde los comienzos del pensamiento moderno de la soberania hasta la lucha de clases proletaria. Madrid: Alianza Editorial.

Schmitt, C. (2005) Teología politica. Cuatro ensayos sobre la soberanía. Buenos Aires: Struhart \& Cia.

Schmitt, C. (2006) Concepto de lo politico. Buenos Aires: Struhart \& Cia.

Svampa, M. (2003) "El populismo imposible y sus actores, 1973-1976", en Daniel James (editor), Nueva historia argentina: Violencia, proscripción y autoritarismo 1955-1976. Volumen 9 (pp. 381-437). Buenos Aires: Sudamericana.

\section{Notas}

1 Sobre las críticas que recibió el proyecto ver Franco (2012), pp. 74-75.

2 Este párrafo es tributario de un intercambio de correos electrónicos con Marina Franco.

3 Los decretos en cuestión fueron el 261, el 2.770, el 2.771 y el 2.772.

4 "Organización de la defensa nacional. Mensaje y proyecto de ley del Poder Ejecutivo" en Argentina, Congreso de la Nación. Diario de sesiones de la Cámara de Senadores,(Buenos Aires: Imprenta del Congreso, 1975), vol. IV, pp. 2890-2897; "Régimen para la defensa nacional" en Argentina. Congreso de la Nación, Diario de sesiones de la Cámara de Diputados,(Buenos Aires: Imprenta del Congreso, 1975), vol. VII, pp. 5031-5087, 5231-5334, documentos citados desde: Ministerio de Defensa, Antecedentes legales y parlamentarios, 1944-1986, pp. 143-150.

5 Ver también las declaraciones del diputado del Partido Comunista, integrado a la Alianza Popular Revolucionaria, Jesús Mira en Ministerio de Defensa, Antecedentes legales y parlamentarios, 1944-1986, p. 235. Ver también las expresiones del diputado oficialista José Lazzarini en Ministerio de Defensa, Antecedentes legales y parlamentarios, 1944-1986, p. 180 y las del diputado del Partido Revolucionario Cristiano Luis Lucena en Ministerio de Defensa, Antecedentes legales y parlamentarios, 1944-1986, pp. 309-310.

6 Para expresiones similares por parte de diputados de otros partidos: en el caso de la UCR ver Ministerio de Defensa, Antecedentes legales y parlamentarios, 1944-1986, p. 27; para el oficialismo ver Ministerio de Defensa, Antecedentes legales y parlamentarios, 1944-1986, p. 35; para el Partido Comunista ver Ministerio de Defensa, Antecedentes legales y parlamentarios, 1944-1986, p. 36 y para el Partido Revolucionario Cristiano ver Ministerio de Defensa, Antecedentes legales y parlamentarios, 1944-1986, pp. 53-54.

7 Ver también las expresiones del diputado intransigente Musacchio en Ministerio de Defensa, Antecedentes legales y parlamentarios, 1944-1986, p. 187.

8 Por el Partido Intransigente ver Ministerio de Defensa, Antecedentes legales y parlamentarios, 1944-1986, p. 184; por el Partido Comunista ver Ministerio de Defensa, Antecedentes legales y parlamentarios, 1944-1986, pp. 238, 241; por la Unión del Pueblo Argentino ver Ministerio de Defensa, Antecedentes legales y parlamentarios, 1944-1986, pp. 260, 261 y por el Partido Revolucionario Cristiano ver Ministerio de Defensa, Antecedentes legales y parlamentarios, 1944-1986, pp. 283-287.

9 Sobre los efectos de la doctrina antisubversiva francesa la Guerra de Argelia, Branche señala: "en algunos puntos, la legislación se hunde en las formas de la 'guerra revolucionaria”. Raphaëlle Branche, La torture et l'Armée pendant la guerre d'Algérie, 1954-1962, (Paris: Gallimard, 2001), p. 108. Traducción propia desde la versión en francés: "sur certains points, la législation se coule dans les formes de la 'guerre révolutionnaire"”.

10 La referencia completa de todas las fuentes que hablan de la reunión está citada en la nota al pie número 12 del texto de Acuña y Smulovitz mencionado en este artículo.

11 Las mayúsculas pertenecen al texto original. 
12 Las mayúsculas pertenecen al texto original.

13 Ver también lo expresado por el diputado Portero en Ministerio de Defensa, Antecedentes legales y parlamentarios, 1944-1986, p. 304. 